\title{
The Development of Demand Identification Model for Poverty Alleviation Subjects Using Fuzzy Proximity
}

\author{
Shuwei Jing $\mathbb{D},{ }^{1}$ Rui Li, ${ }^{2}$ Junai Yan, ${ }^{1}$ and Sujiao Zhang $\mathbb{D}^{1}$ \\ ${ }^{1}$ School of Management Science and Engineering, Shanxi University of Finance and Economics, Taiyuan, China \\ ${ }^{2}$ College of Management and Economics, Tianjin University, Tianjin, China \\ Correspondence should be addressed to Shuwei Jing; jingshuwei.abcd@aliyun.com
}

Received 10 April 2019; Accepted 3 December 2019; Published 17 December 2019

Academic Editor: Alberto Cavallo

Copyright (c) 2019 Shuwei Jing et al. This is an open access article distributed under the Creative Commons Attribution License, which permits unrestricted use, distribution, and reproduction in any medium, provided the original work is properly cited.

Given that there are problems of difficulty to identify accurately the poverty alleviation subjects' demands. This research puts forward and applies the fuzzy proximity method on the basis of the fuzzy set theory. The method can identify accurately the demands of poverty alleviation subjects. This study calculated the fuzzy proximity vector and the positive and negative ideal grades of the four demand types, according to six poverty characteristic indexes. The demand types are determined. Then, the paper takes a case about the demand identification of a poverty alleviation subject in a village, Shanxi province in China. The application result showed that (1) the demand identification model can help identify accurately the demands of poverty alleviation subjects; (2) the poverty alleviation strategies provide a reference for the government to carry out poverty alleviation work.

\section{Introduction}

Poverty is a common problem in the whole world. In China, population is nearly 1.4 billion, poverty would be seen everywhere in villages. The main problems of poverty alleviation were that some poor households have not gained poverty alleviation policy benefits and some poverty alleviation subjects were returning to poverty due to without policies benefits. Such phenomenon has led to inefficiency in poverty alleviation. The fundamental reason is that the poverty alleviation subjects' demand has not been identified accurately. According to the current poverty alleviation situation in China, General Secretary of China, Xi, Jin-Ping, put forward that the thought of "Taking targeted measures to help people lift themselves out of poverty" in 2013. The connotation of this thought includes accurate identification, precision help, precision management, and accurate assessment. The government can implement targeted strategy to achieve the goal of getting rid of poverty permanently. Accurate identification as the primary task of precision poverty alleviation is the basis for implementing a series of precise help, which is of great significance to the government to carry out poverty alleviation work effectively.
In order to help the government to carry out the poverty alleviation work efficiently, this study focuses on the identification of the poverty alleviation subjects' demands, trying to find out what method can identify efficiently the demands of the poverty alleviation subjects. The fuzzy proximity method is widely used in the identification of the life cycle in enterprises. Based on literature studies, this study tries to use the fuzzy proximity method to identify the demands of the poverty alleviation subjects.

The overall structure of this paper is as follows. The literature reference is given in Section 2. The analysis of demand types and characteristic for the poverty alleviation subjects are introduced in Section 3. The determination of demand types using the fuzzy proximity method is given in Section 4 . A case study about the demand identification of a poor rural household, Shanxi province in China, is given in Section 5. Conclusions are finally presented in Section 6. The technology roadmap is shown in Figure 1.

\section{Literature Review}

There are some literature studies that research on poverty as follows: (1) View of poverty types: many scholars studied the 


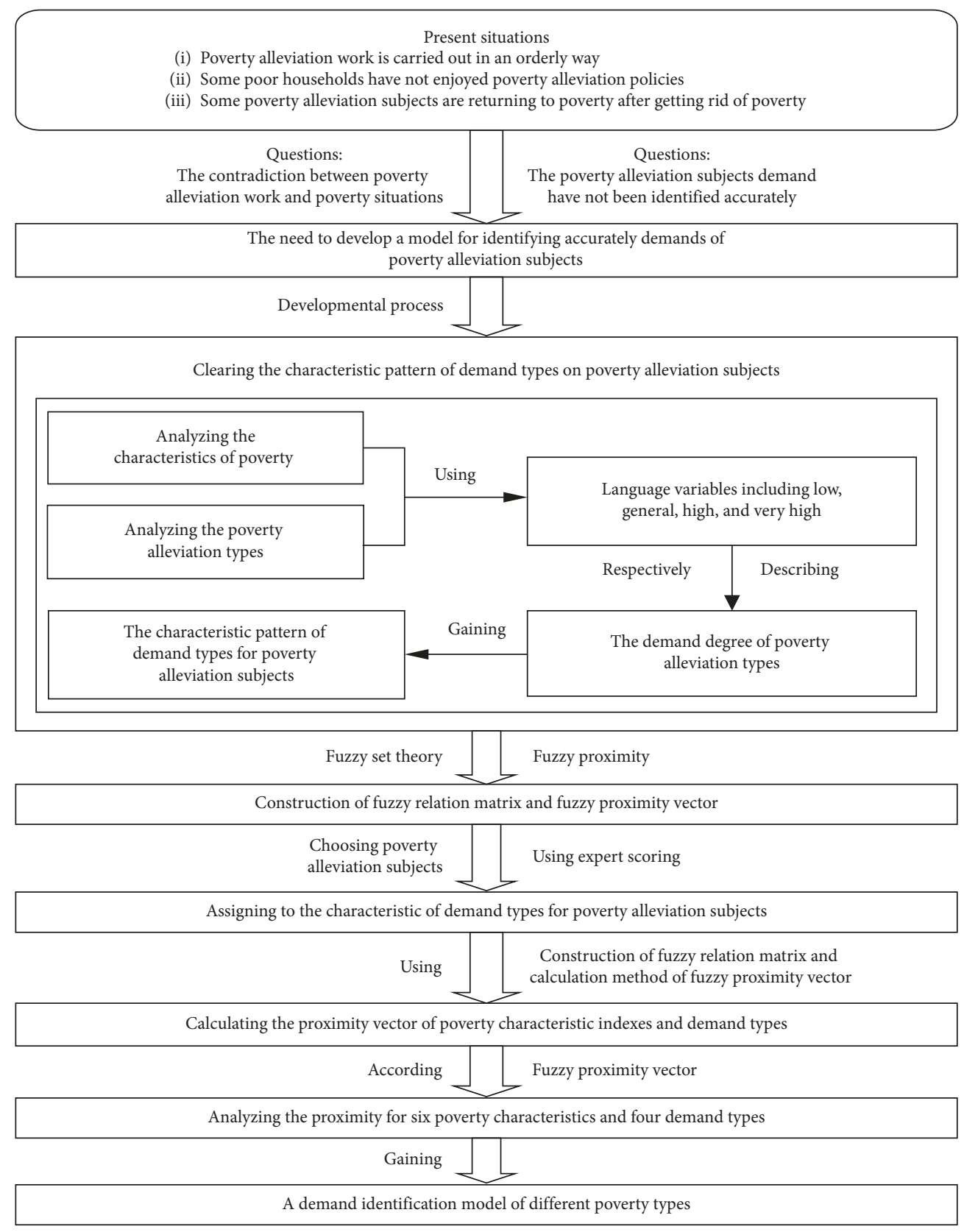

Figure 1: The development process of the demand identification model.

types of poverty $[1,2]$. Poverty should be divided into longterm poverty, short-term poverty, and selective poverty [3]. Some scholars divided poverty into multiple types with China's national conditions from multiple angles through analyzing the past poverty alleviation process $[4,5]$. Poverty should be divided into persistent poverty, temporary poverty, and selective poverty and do the empirical analysis as discussed by [6]. Other scholars divided the poverty into ecological poverty, regional poverty, and national poverty based on geographical environment, national cultural, and so on. [7]. Some authors divided the poverty into economic poverty, knowledge-based poverty, and institutional poverty based on the causes and manifestations of poverty [8]. (2) View of poverty identification: the scholars emphasized the importance of precision identification based on expounding precision poverty alleviation [9-11]). Other researchers evaluated the poverty degree of the farmer using the farmer's asset index and the poverty index based on the quasi-experimental method and then evaluated the effect of poverty alleviation by the double differential method $[12,13]$. Other scholars used the survey data to study the targeting of poor counties and villages, found that the targeting accuracy was low and then made the relevant recommendations $[14,15]$. Many scholars measured the poverty situation of the farmers by constructing the poverty measurement indexes using UNDP on the MPI method, double critical value method, AF multidimensional poverty measurement, participatory poverty assessment (PPA), monetary approach to poverty 
assessment, multidimensional poverty indicators (MDI), and other methods from income, education, health, living standards, and other aspects [16-30]. (3) View of poverty measurement: whether it is measure of quality of life, measure of happiness degree, or measure of poverty degree, many scholars break the traditional one-dimensional measure method and propose to measure from multiple dimensions and establish properly evaluation indexes [3133]. More and more authors used fuzzy set theory [34] to measure poverty from multidimensional perspective [3539]. (4) View of poverty alleviation strategy: the scholars put forward some suggestions on poverty identification, poverty alleviation pattern, and helping mechanism according to the problems existing in the current poverty alleviation work $[7,40-48]$.

There are some literature studies to research on the content of precision poverty alleviation, poverty classification and measurement, and poverty alleviation measurement. Some scholars pointed out that poverty alleviation policies should fit the demands of the rural poor [49], which indicates the direction for the government's poverty alleviation based on the demands of the rural poor. But, few scholars study the demands of the poverty alleviation subjects. Therefore, the paper puts forward a method to identify the demands of poverty alleviation subjects based on the theory of fuzzy sets. It aims to help the government to carry out the poverty alleviation work efficiently through the effective identification of the poverty alleviation subjects' demands which is of great significance to achieve the goal of throwing off poverty thoroughly under Chinese existing standards in 2020.

\section{The Analysis on Demand Types and Characteristic of the Poverty Alleviation Subjects}

3.1. The Division of Demand Types on the Poverty Alleviation Subjects. The key to targeted poverty alleviation is that adjusting measures to people, local conditions, the reason, and type of poverty. We should "suit the remedy to the case," according to the different demands of poverty alleviation subjects. There are some literature studies to research on the reason and pattern of poverty. However, there are a few scholars to research on the demand of poverty alleviation subjects. Therefore, this paper divides the demand of poverty alleviation subjects into four help types on the basis of the existing researches as follows:

(1) The first is the living security type. This support provides the help on subsistence allowances, medical security, and so on. The poverty alleviation subjects having poor living conditions or illness have a higher demand for this support. The government should solve the most basic problems for them. Some poverty alleviation subjects have a low demand for this support such as the people who live in the remote place or drop out of school. The reason is that they all have labor capacity. They hope to change the poor current conditions by their own labor.
(2) The second is the skill training type. This support mainly provides the skill training for poverty alleviation subjects who labor capacity or willing to work. Some poverty alleviation subjects have a higher demand for this support such as the people who drop out of school, have high labor enthusiasm, or have willing to develop themselves. There are others who have poor living conditions and live in the remote place have low demand for this support. These poverty alleviation subjects want to get rid of poverty by learning some skills on the basis of solving basic life problems firstly. Besides, the poverty alleviation subjects who get illness also have low demand for this support because of the limited labor capability.

(3) The third is the funding support type. This support mainly provides the funding for the poverty alleviation subjects that are willing to start a business or develop industry. The poverty alleviation subjects who are willing to develop themselves want to get a part of venture capital from the government. Therefore, these poverty alleviation subjects have a higher demand for this support. Others who drop out of school and have a higher labor enthusiasm have a higher demand for this support. Some poverty alleviation subjects have a general demand for this support such as the people who have poor living conditions and live in the remote place. However, the poverty alleviation subjects who have illness have a low demand for this support.

(4) The fourth is the infrastructure construction type. This support mainly provides water, electricity, and roads and communication services for the poverty alleviation subjects. The poverty alleviation subjects in the remote place have a higher demand for this support. The poverty alleviation subjects for poor living conditions also have a higher demand for this support. The poverty alleviation subjects for dropping out of school have a higher demand for this support. The reason for dropping out of school is that infrastructure is inadequate. Therefore, it is important to build infrastructure for them. However, the poverty alleviation subjects who have labor capability have general demand for this support. Besides, the poverty alleviation subjects who have illness have low demand for this support.

\subsection{The Characteristic Pattern of Demand Types on Poverty} Alleviation Subjects. There are some literature studies to research on establishing poverty indexes from multiple dimensions. The poverty indexes are shown in Table 1.

Wang Sangui, director of the antipoverty research center at Renmin University of China, point out that "mental poverty" is the biggest enemy of poverty alleviation. "Some poor people and poor families do not have a strong desire for self-development and rely more on external support rather than take the initiative to alleviate poverty. Some poor people and poor families have the desire to get rid of poverty 
TABLE 1: The literature collation on multidimensional poverty indexes.

\begin{tabular}{|c|c|c|}
\hline Dimensionality & Indexes & Authors \\
\hline Income & Annual per capita net income & $\begin{array}{l}\text { He et al. [29]; Hagenaars [16]; Alkire and Foster [20]; } \\
\text { Yang and Wang [28]; Wang et al. [27]; Sun et al. [24]; } \\
\text { Jiang et al. [22]; Chen [25] }\end{array}$ \\
\hline Living standard & $\begin{array}{l}\text { Housing structure, living fuel, household appliances, } \\
\text { sanitary facilities, and durable goods }\end{array}$ & $\begin{array}{l}\text { Alkire and Foster [20]; Wang and Alkire [17]; Guo } \\
\text { [23]; Yang and Wang [28]; Wang et al. [27]; Gao and } \\
\text { Ma [26]; Sun et al. [24]; Zou and Fang [21]; Chen [25] }\end{array}$ \\
\hline Education & $\begin{array}{l}\text { Average age of schooling, child enrollment rate, and } \\
\text { learning situation of school-age children }\end{array}$ & $\begin{array}{l}\text { Alkire and Foster [20]; Guo [23]; Yang and Wang } \\
\text { [28]; Wang and Alkire [17]; Li [19]; Wang et al. [27]; } \\
\text { Gao and Ma [26]; Sun et al. [24]; Zou and Fang [21]; } \\
\text { Jiang et al. [22]; Chen [25] }\end{array}$ \\
\hline Health & $\begin{array}{l}\text { The number of patients, timeliness of cure, } \\
\text { participation of cooperative medical treatment, and } \\
\text { participation of medical insurance }\end{array}$ & $\begin{array}{l}\text { Guo [23]; Yang and Wang [28]; Wang and Alkire } \\
\text { [17]; Li [19]; Wang et al. [27]; Gao and Ma [26]; Sun } \\
\text { et al. [24]; Jiang et al. [22]; Chen [25] }\end{array}$ \\
\hline $\begin{array}{l}\text { Infrastructure } \\
\text { construction }\end{array}$ & Water, electricity, roads, and communication & $\begin{array}{l}\text { Guo [24]; Yang and Wang [28]; Wang and Alkire } \\
\text { [19]; Li [19]; Wang et al. [27]; Gao and Ma [26]; Sun } \\
\text { et al. [24]; Zou and Fang [27]; Jiang et al. [26] }\end{array}$ \\
\hline
\end{tabular}

but the lack of initiative spirit, which is two concrete embodiments of "mental poverty" in some parts of China." (Targeted poverty alleviation needs "Getting out of poverty in mental," Kwangmyong Net, August 22, 2016 (http://news. gmw.cn/2016-08/22/content_21567455.html).). Therefore, the paper selects two indexes to reflect the mental poverty of poverty alleviation subjects as follows: "labor enthusiasm" index and "self-development expectations" index. However, this paper's research subject is poor people and we often use "income" to measure whether people are poor. Therefore, we do not include "income" index in this research.

To sum up, this paper selects six poverty indexes as follows: "The bad degree of living conditions, communication blocking degree, education poverty degree, nonhealth degree, labor enthusiasm, and self-development expectations." Then, we use "low, general, high, and very high" to describe the demand degree of poverty alleviation subjects to four demand types that are "the living security, the skill training, the funding support, and the infrastructure construction." The characteristic pattern of demand types on poverty alleviation subjects is shown in Table 2 .

This paper measures the poverty from the six aspects which are as follows:

(1) The bad degree of living conditions: we mainly investigate the poverty alleviation subjects from their housing structure, living fuel, and sanitation facilities

(2) Communication blocking degree: we mainly investigate the poverty alleviation subjects that live in the remote place from the areal transportation, electricity, and communication

(3) Education poverty degree: we consider the adult of education under five years as the education poverty [19]

(4) Nonhealth degree: we mainly investigate whether the poverty alleviation subjects suffer from disease, whether they suffer from congenital disease, chronic diseases, or other major diseases, whether they can be treated in time, and whether they participate in cooperative medical treatment

(5) Labor enthusiasm: we mainly investigate the labor capacity and enthusiasm of poverty alleviation subjects and whether they have the initiative spirit

(6) Self-development expectations: we mainly investigate whether the poverty alleviation subjects are willing to start a business or develop industry or they just want to rely on external support to get rid of poverty

\section{The Determination of Demand Types Based on the Fuzzy Proximity Method}

4.1. Construction of Fuzzy Relation Matrix. Firstly, we establish the expert scoring team and grade for the living current conditions of poverty alleviation subjects based on six poverty characteristic indexes using the ten-point system (one point indicates that there is almost no characteristic, while 10 points indicate that there is a certain characteristic). We use the Cauchy membership function [50-52] to represent that the membership degree of $x$ to language variables "low, general, high, and very high." The membership function is shown as the following equations:

$$
\begin{aligned}
& \mu_{\text {Low }}(x)= \begin{cases}1, & 1 \leq x \leq 3, \\
{\left[1+\left(\frac{x-3}{2}\right)^{2}\right]^{-1},} & 3 \leq x \leq 10\end{cases} \\
& \mu_{\text {General }}(x)=\left[1+\left(\frac{x-5}{2}\right)^{2}\right]^{-1}, \quad 1 \leq x \leq 10 \text {, } \\
& \mu_{\text {High }}(x)=\left[1+\left(\frac{x-8}{2}\right)^{2}\right]^{-1}, \quad 1 \leq x \leq 10,
\end{aligned}
$$


TABLE 2: The characteristic pattern of demand types on poverty alleviation subjects.

\begin{tabular}{|c|c|c|c|c|}
\hline Characteristic indexes & $\begin{array}{l}\text { The living security } \\
\text { type }\end{array}$ & $\begin{array}{l}\text { The skill training } \\
\text { type }\end{array}$ & $\begin{array}{l}\text { The funding support } \\
\text { type }\end{array}$ & $\begin{array}{c}\text { The infrastructure construction } \\
\text { type }\end{array}$ \\
\hline $\begin{array}{l}\text { The bad degree of living } \\
\text { conditions }\end{array}$ & Very high & High & General & High \\
\hline $\begin{array}{l}\text { Communication blocking } \\
\text { degree }\end{array}$ & Low & High & General & Very high \\
\hline Education poverty degree & Low & Very high & High & High \\
\hline Nonhealth degree & Very high & General & Low & Low \\
\hline Labor enthusiasm & Low & Very high & High & General \\
\hline Self-development expectations & Low & Very high & Very high & General \\
\hline
\end{tabular}

$$
\mu_{\text {Very high }}(x)=\left\{\begin{array}{l}
1, \quad 9 \leq x \leq 10, \\
{\left[1+\left(\frac{x-9}{2}\right)^{2}\right]^{-1}, \quad 1 \leq x<9 .}
\end{array}\right.
$$

We use $U$ to represent expert scoring set, $U=\left\{u_{1}\right.$, $\left.u_{2}, u_{3}, u_{4}, u_{5}\right\}$. We use $V$ to represent the language variable set, $V=\left\{v_{1}, v_{2}, v_{3}, v_{4}\right\}=\{$ low, general, high, very high $\}$. We use $W$ to represent four demand type sets, $W=\left\{w_{1}\right.$, $\left.w_{2}, w_{3}, w_{4}\right\}=\{$ the living security type, the skill training type, the funding support type, and the infrastructure construction type\}.

We get the $U \longrightarrow V$ relationship according to equations (1)-(4). This relationship represents that $u_{i} \in U(1 \leq i \leq 6)$ is evaluated as a fuzzy subset of $V$. The fuzzy subset is expressed as $\widetilde{s_{i}}=\left(s_{1 i}, s_{2 i}, s_{3 i}, s_{4 i}\right)^{T}$, and then we get a fuzzy relation matrix $\widetilde{S}$. Meanwhile, we get $U \longrightarrow W$ relationship according to Table 2 which is the relationship between language variables and four demand types. The poverty characteristic indexes $u_{i} \in U(1 \leq i \leq 6)$ are evaluated as a fuzzy subset of demand type $W$. The fuzzy subset is expressed as $\widetilde{r}_{i}=\left(r_{1 i}, r_{2 i}, r_{3 i}, r_{4 i}\right)^{T}$, and then we get a fuzzy relation matrix $\widetilde{R}$.

4.2. The Calculation on Proximity of Demand Types. There are some scholars to study the availability of asymmetric fuzzy proximity [53]. We define the characteristic fuzzy subset of four demand types as $\widetilde{D}_{j}=(0, \Lambda, 1, \Lambda, 0)(j=1,2,3,4)$, that is, $\widetilde{D}_{1}=(1,0,0,0), \widetilde{D}_{2}=(0,1,0,0), \widetilde{D}_{3}=(0,0,1,0)$, and $\widetilde{D}_{4}=(0,0,0,1)$. The asymmetric fuzzy proximity is as follows:

$$
N(\widetilde{A}, \widetilde{B})=1-\frac{2}{n(n+1)} \bullet \sum_{k=1}^{n}\left|\mu_{A}\left(v_{k}\right)-\mu_{B}\left(v_{k}\right)\right| \bullet k .
$$

In equation (5), $\mu_{A}(\bullet)$ represents the membership degree of the fuzzy subset $\widetilde{A}$. $\mu_{B}(\bullet)$ represents the membership degree of the fuzzy subset $\widetilde{B}$.

We use $N\left(\widetilde{r}_{i}, \widetilde{D}_{j}\right)$ to represent the proximity of $\tilde{r}_{i}(i=$ $1,2,3,4,5,6)$ and $\widetilde{D}_{j}(j=1,2,3,4) . \widetilde{r}_{i}$ and $\widetilde{D}_{j}$ are required for standardized transformation simultaneously because of the different effects of difference in membership degrees for each grade. The concrete measures of standardizing $\widetilde{r}_{i}$ are as follows: we need to put $r_{j i}$ in the first place, $\forall j^{\prime}, j^{\prime \prime}$ if $\left|j^{\prime}-j\right|<\left|j^{\prime \prime}-j\right|$ ( $j^{\prime \prime}$ is more far away from $j$ ), we need to put $r_{j^{\prime} i}$ in front of $r_{j^{\prime \prime} i}$. If $\left|j^{\prime}-j\right|=\left|j^{\prime \prime}-j\right|$ and $j^{\prime}<j^{\prime \prime}$, we also need to put $r_{j^{\prime} i}$ in front of $r_{j^{\prime \prime} i}$. Then, we use $\widetilde{r}_{i}^{j}$ to represent standardized $\widetilde{r}_{i}$. Similarly, we use $\widetilde{D}_{1}$ to represent standardized $\widetilde{D}_{j}$. Therefore, $N\left(\tilde{r_{i}^{j}}, \widetilde{D}_{1}\right)$ is used to represent $N\left(\widetilde{r}_{i}, \widetilde{D}_{j}\right)$.

We get the asymmetric fuzzy proximity of the characteristic subset. The characteristic subset is formed by a certain poverty index and each demand type. Therefore, the above asymmetric fuzzy proximity is represented as follows:

$$
\begin{aligned}
\tilde{Z}_{i} & =\left(Z_{1 i}, Z_{2 i}, Z_{3 i}, Z_{4 i}\right)^{T} \\
& =\left(N\left(\widetilde{r}_{i}, \widetilde{D}_{1}\right), N\left(\tilde{r}_{i}, \widetilde{D}_{2}\right), N\left(\tilde{r}_{i}, \widetilde{D}_{3}\right), N\left(\tilde{r}_{i}, \widetilde{D}_{4}\right)\right)^{T} .
\end{aligned}
$$

Therefore, the asymmetric fuzzy proximity of $U=\left\{u_{1}\right.$, $\left.u_{2}, \Lambda, u_{6}\right\}$ under all poverty characteristic indexes is as follows:

$$
Z=\left(Z_{i j}\right)_{4 \times 6}=\left(\widetilde{Z}_{1}, \widetilde{Z}_{2}, \Lambda, \widetilde{Z}_{6}\right)
$$

According to the Technique for Order Preference by Similarity to an Ideal Solution (TOPSIS) method [53], we define $W^{+}$and $W^{-}$as virtual evaluation grade. $W^{+}$represents that poverty characteristic indexes are the closest to each demand type (defined by $\widetilde{C}^{+}$). $W^{-}$represents that poverty characteristic indexes are the farthest to each demand type (defined by $\widetilde{C}^{-}$). The functions are as follows:

$$
\begin{aligned}
\widetilde{C}^{+}=\left(C_{1}^{+}, C_{2}^{+}, \Lambda, C_{6}^{+}\right)= & \left(\max _{j=1,2,3,4} N\left(\tilde{r}_{1}, \widetilde{D}_{j}\right), \max _{j=1,2,3,4}\right. \\
& \left.\cdot N\left(\widetilde{r}_{2}, \widetilde{D}_{j}\right), \Lambda, \max _{j=1,2,3,4} N\left(\tilde{r}_{6}, \widetilde{D}_{j}\right)\right),
\end{aligned}
$$

$$
\begin{aligned}
\widetilde{C}^{-}=\left(C_{1}^{-}, C_{2}^{-}, \Lambda, C_{6}^{-}\right)= & \left(\min _{j=1,2,3,4} N\left(\widetilde{r}_{1}, \widetilde{D}_{j}\right), \min _{j=1,2,3,4}\right. \\
& \left.\cdot N\left(\tilde{r}_{2}, \widetilde{D}_{j}\right), \Lambda, \min _{j=1,2,3,4} N\left(\tilde{r}_{6}, \widetilde{D}_{j}\right)\right) .
\end{aligned}
$$

In order to get the determination of the six poverty characteristic indexes under each demand type, we need to compare all proximities that are formed by each demand type in set $W$ and the positive and negative ideal grades. $\widetilde{C}_{j}$ represents proximity vector of poverty characteristic indexes and demand type $j$ :

$$
\begin{aligned}
\widetilde{C}_{j}= & \left(C_{1 j}, C_{2 j}, \Lambda, C_{6 j}\right)=\left(N\left(\tilde{r}_{1}, \widetilde{D}_{j}\right),\right. \\
& \left.\cdot N\left(\widetilde{r}_{2}, \widetilde{D}_{j}\right), \Lambda, N\left(\widetilde{r}_{6}, \widetilde{D}_{j}\right)\right), \quad j=1,2,3,4 .
\end{aligned}
$$


We use symmetrical proximity to measure the difference and proximity between $\widetilde{C}_{j}$ and ideal grades $\left(\widetilde{C^{+}}\right.$and $\left.\widetilde{C^{-}}\right)$. The concrete calculation is as follows:

We calculate first

$$
\begin{gathered}
\delta\left(\widetilde{C}^{+}, \widetilde{C}_{j}\right)=\frac{\sum_{k=1}^{6} \mu_{C_{j}}\left(u_{k}\right)}{\sum_{k=1}^{6} \mu_{C^{+}}\left(u_{k}\right)}, \\
\delta\left(\widetilde{C}^{-}, \widetilde{C}_{j}\right)=\frac{\sum_{k=1}^{6} \mu_{C^{-}}\left(u_{k}\right)}{\sum_{k=1}^{6} \mu_{C_{j}}\left(u_{k}\right)} .
\end{gathered}
$$

Then, we calculate $\delta\left(\widetilde{C}^{+}, \widetilde{C}_{j}\right) / \delta\left(\widetilde{C}^{-}, \widetilde{C}_{j}\right)$, if

$$
\frac{\delta\left(\widetilde{C}^{+}, \widetilde{C}_{p}\right)}{\delta\left(\widetilde{C}^{-}, \widetilde{C}_{p}\right)}=\max _{j=1,2,3,4} \frac{\delta\left(\widetilde{C}^{+}, \widetilde{C}_{j}\right)}{\delta\left(\widetilde{C}^{-}, \widetilde{C}_{j}\right)} .
$$

The above equation indicates that we need to provide the help represented by $w_{p}$ for the poverty alleviation subjects firstly.

\section{Case Study}

5.1. Case Analysis. In order to verify the feasibility and scientificity of the demand identification model, this paper selects an interview of poverty alleviation subject in a village, Shanxi province in China in 2017. And then, the paper studies mainly the demand identification of the poverty alleviation subject. The above village has 94 households with a population of 198, which is supported by single crop farming and labor export. This village is one of the key poverty alleviation villages in its village. The paper takes a poor household of the above village as the research subject. According to field research, we know that this poor household suffers from rheumatoid arthritis, lack of labor capability. He has a poor living conditions and the main source of income is the security funds and poverty alleviation funds provided by the government. Besides, he has low labor enthusiasm and self-development expectations. This poverty alleviation subject hopes that the government can increase the proportion of medical reimbursement so that it could reduce long-term medication costs.

In order to determine accurately the demand types of the above poor household, the paper uses back-to-back communication method according to principle of "Delphi method." And then, we invite two staff members from the county's poverty alleviation office and three university experts to mark for living current conditions of the above poor household. After two rounds of consultation, the mark tends to be centralized, and then we obtain the mark set of six poverty characteristic indexes $U=\{9,5,8,9,4,5\}$ (see in Table 3 and Figure 2).

First, we put $x=9$ into equations (1)-(4) as follows:

$$
\begin{aligned}
\mu_{\text {Low }}(9) & =\left[1+\left(\frac{9-3}{2}\right)^{2}\right]^{-1}=0.1000, \\
\mu_{\text {General }}(9) & =\left[1+\left(\frac{9-5}{2}\right)^{2}\right]^{-1}=0.2000, \\
\mu_{\text {High }}(9) & =\left[1+\left(\frac{9-8}{2}\right)^{2}\right]^{-1}=0.8000, \\
\mu_{\text {Very high }}(9) & =\left[1+\left(\frac{9-9}{2}\right)^{2}\right]^{-1}=1.0000 .
\end{aligned}
$$

Then, we get $\widetilde{s_{1}}=(0.1000,0.2000,0.8000,1.0000)^{T}$. According the above steps, the fuzzy relation matrix $\widetilde{S}$ is obtained as follows:

$$
\widetilde{S}=\left[\begin{array}{llllll}
0.1000 & 0.5000 & 0.1379 & 0.1000 & 0.8000 & 0.5000 \\
0.2000 & 1.0000 & 0.3077 & 0.2000 & 0.8000 & 1.0000 \\
0.8000 & 0.3077 & 1.0000 & 0.8000 & 0.2000 & 0.3077 \\
1.0000 & 0.2000 & 0.8000 & 1.0000 & 0.1379 & 0.2000
\end{array}\right]
$$

Then, we get the fuzzy relation matrix $\widetilde{R}$ of $U \longrightarrow W$ according to Table 1 . The relationship between language variables and four demand types is as follows:

$$
\widetilde{R}=\left[\begin{array}{llllll}
1.0000 & 0.5000 & 0.1379 & 1.0000 & 0.8000 & 0.5000 \\
0.8000 & 0.3077 & 0.8000 & 0.2000 & 0.1379 & 0.2000 \\
0.2000 & 1.0000 & 1.0000 & 0.1000 & 0.2000 & 0.2000 \\
0.8000 & 0.2000 & 1.0000 & 0.1000 & 0.8000 & 1.0000
\end{array}\right] .
$$

According to equations (5)-(7), the decision matrix $\widetilde{Z}$ is obtained as follows:

$$
\widetilde{Z}=\left[\begin{array}{llllll}
0.4600 & 0.5085 & 0.0538 & 0.8900 & 0.5724 & 0.4500 \\
0.4000 & 0.4508 & 0.2524 & 0.6500 & 0.3738 & 0.3600 \\
0.1200 & 0.6785 & 0.4848 & 0.4400 & 0.3324 & 0.3800 \\
0.3000 & 0.4277 & 0.5048 & 0.4300 & 0.5786 & 0.7000
\end{array}\right] .
$$

According to equations (8) and (9), the positive and negative ideal grades are obtained as follows:

$$
\begin{aligned}
& \widetilde{C}^{+}=\left(\begin{array}{llllll}
0.4600 & 0.6785 & 0.5048 & 0.8900 & 0.5786 & 0.7000
\end{array}\right), \\
& \widetilde{C}^{-}=\left(\begin{array}{lllllll}
0.1200 & 0.4277 & 0.0538 & 0.4300 & 0.3324 & 0.3600
\end{array}\right) .
\end{aligned}
$$

According to equation (10), the proximity vector of poverty characteristic indexes and demand types are obtained as follows: 
TABLE 3: The results of expert scoring.

\begin{tabular}{lc}
\hline Characteristic indexes & Mean \\
\hline The bad degree of living conditions & 9 \\
Communication blocking degree & 5 \\
Education poverty degree & 8 \\
Nonhealth degree & 9 \\
Labor enthusiasm & 4 \\
Self-development expectations & 5 \\
\hline
\end{tabular}

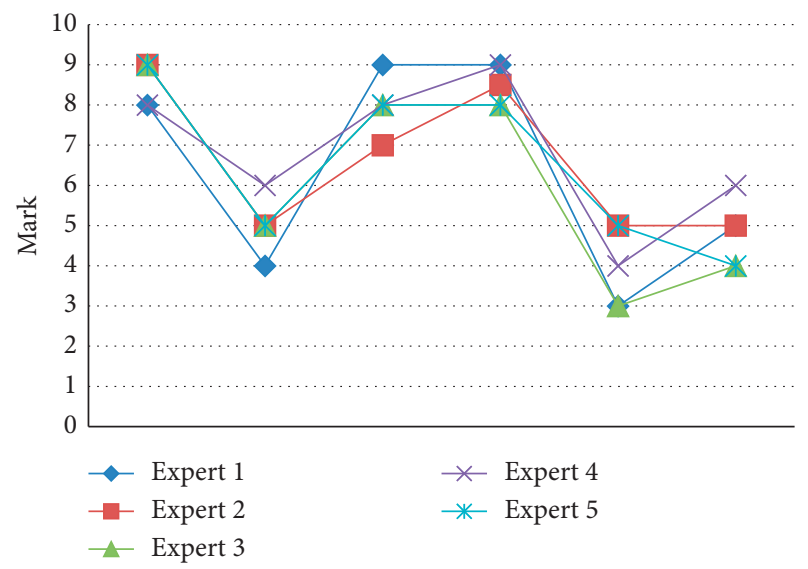

Figure 2: The tendency of expert scoring.

$$
\begin{aligned}
& \widetilde{C}_{1}=\left(\begin{array}{llllll}
0.4600 & 0.5085 & 0.0538 & 0.8900 & 0.5724 & 0.4500
\end{array}\right), \\
& \widetilde{C}_{2}=\left(\begin{array}{llllll}
0.4000 & 0.4508 & 0.2524 & 0.6500 & 0.3738 & 0.3600
\end{array}\right), \\
& \widetilde{C}_{3}=\left(\begin{array}{llllll}
0.1200 & 0.6785 & 0.4848 & 0.4400 & 0.3324 & 0.3800
\end{array}\right), \\
& \widetilde{C}_{4}=\left(\begin{array}{llllll}
0.3000 & 0.4277 & 0.5048 & 0.4300 & 0.5786 & 0.7000
\end{array}\right)
\end{aligned}
$$

According to equations (11) and (12), we get the results as follows:

$$
\begin{aligned}
& \frac{\delta\left(\widetilde{C}^{+}, \widetilde{C}_{1}\right)}{\delta\left(\widetilde{C}^{-}, \widetilde{C}_{1}\right)}=1.3106, \\
& \frac{\delta\left(\widetilde{C}^{+}, \widetilde{C}_{2}\right)}{\delta\left(\widetilde{C}^{-}, \widetilde{C}_{2}\right)}=0.9412, \\
& \frac{\delta\left(\widetilde{C}^{+}, \widetilde{C}_{3}\right)}{\delta\left(\widetilde{C}^{-}, \widetilde{C}_{3}\right)}=0.9028, \\
& \frac{\delta\left(\widetilde{C}^{+}, \widetilde{C}_{4}\right)}{\delta\left(\widetilde{C}^{-}, \widetilde{C}_{4}\right)}=1.3163 .
\end{aligned}
$$

According to the above results of identification, the relevant departments should provide the help about the infrastructure construction first and provide the help about the living security at the same time. This decision is consistent with the actual situation of poverty alleviation in China. On the surface, this poor household has more demands on living and medical treatment. However, the infrastructure construction is a prerequisite for all kinds of helps in the long term. The relevant departments should improve the infrastructure construction; meanwhile, they can provide other help for poverty alleviation subjects, so as to get rid of poverty thoroughly.

5.2. The Analysis on Strategy Selection of Different Demand Types. According to the research results, the infrastructure construction plays an important and fundamental role in the poverty alleviation. The infrastructure construction is also the important material foundation of improving the life for the poverty alleviation subjects. Meanwhile, it is a guarantee of achieving all kinds of help. The perfect infrastructure construction is an important prerequisite to realize complete poverty alleviation. The rural areas have inadequate infrastructure supplies due to the lack of funds. However, the government is often unable to provide funding constantly for infrastructure construction. Therefore, we suggest using PPP (Public and Private Partnerships) pattern [54] to provide funds for poverty alleviation. This pattern can provide public goods and services for the rural infrastructure construction through the cooperation between the government and the private sectors. The government can get more funds and technical support in the above cooperation, and the private organizations can expand their market demand [55]. At the same time, the government can provide living security help for poverty alleviation. The helping ways are as follows: Firstly, the poverty alleviation subjects can participate in cooperative medical. The poverty alleviation subjects that having illness can reduce medical costs by participating in cooperative medical and reimbursement of medical expenses. Secondly, the government can provide medical assistance, including registration fees, treatment fees, hospitalization fee, and other preferential policies. Besides, the government can allocate funds to set up relief fund for the poverty alleviation subjects who have serious disease. Thirdly, the disabled can apply for living subsidies. The poverty alleviation subjects who have no labor capability can apply for social assistance and security. Fourthly, the government can benefit from more poverty alleviation subjects by reducing the standard of five guarantees and subsistence allowances. The basic life difficulties of poverty alleviation subjects can be solved through the above ways.

According to Maslow's hierarchy of needs theory, only by solving the problem of survival can we achieve a higher level of development on this basis. The government should provide the skill training or funding support according to poverty alleviation subjects' demands after the basic living is guaranteed. The government can implement the following strategies for poverty alleviation subjects with skill training demands:

Firstly, the government should encourage poverty alleviation subjects to develop characteristic industries. 
The different regions have different characteristic agriculture and forestry due to geographical location, and the poverty alleviation subjects can develop characteristic industries with the help of the government.

Secondly, the poverty alleviation subjects can join farmers' professional cooperatives. In order to carry out agricultural production and management, they can participate in the cooperatives about forestry and aquaculture, according to their own demands and capability.

Thirdly, the poverty alleviation subjects can participate in the skill training, nursing training, and other projects with the help of the government. The government can implement the following strategies for poverty alleviation subjects with funding support demands: aiming at the poverty alleviation subjects who drop out of school, firstly, they can apply for student loans and enjoy the state grants. Secondly, the government should exempt the tuition, book fees, and provide living allowance for the poor students. Aiming at the poverty alleviation subjects who are lacking of funds, firstly, the poverty alleviation subjects can apply for special funds. Secondly, they can develop tourism and participate in the photovoltaic power generation program, and so on. There is an opportunity for parts of poverty alleviation subjects. They can achieve self-development through the skill training and funding support. Meanwhile, the poverty alleviation subjects can get rid of poverty thoroughly.

In conclusion, poverty alleviation has a long way to go. In order to achieve complete poverty alleviation, the relevant departments should cultivate the ability of creating value for the poverty alleviation subjects on the basis of solving the basic living problems of the poverty alleviation subjects. The economists, represented by [56], construct a new development view about capability, arguing that poverty should be defined as lack of capability. Some scholars argue that the effective way to solve poverty is to improve capability that resists the risk of poverty [57]. Therefore, the government should pay attention to improve the labor capability of poverty alleviation subjects. The government can add the policy of cultivating human capital [58] so that it can improve the capability of resisting the risk of poverty through taking some measures rather than rescuing them after they are in poverty.

\section{Conclusions}

Relying on existing research, the paper proposed a method of precision identification of the demands of poverty alleviation subjects based on fuzzy set theory. The paper took a case about the demand identification of a poverty alleviation subject in a village, Shanxi province in China, and determined the demand types. The conclusions are as follows: the government should give priority to the infrastructure constructions from water, electricity, road, communication, and other aspects. Meanwhile, the relevant departments should provide the help on subsistence allowances, medical security, and so on. On this basis, the relevant departments should take measures according to the demands of the poverty alleviation subjects. The above researches show that

(1) The fuzzy proximity method can identify precisely the demands of the poverty alleviation subjects and help the relevant departments to adjust measures to poverty alleviation subjects.

(2) The infrastructure construction plays an important and fundamental role in the poverty alleviation. In order to achieve complete poverty alleviation, the government should play infrastructure construction on the first place of poverty alleviation. The infrastructure construction is a guarantee of achieving all kinds of helps.

(3) The above research provides the theoretical and practical basis for implementation of precision poverty alleviation, which can drive the process of poverty alleviation in China.

However, this paper just takes one case due to the limitation of space. We can take more cases to verify the feasibility and scientificity of using the fuzzy proximity method to identify the demand types of the poverty alleviation subjects. Meanwhile, we use Delphi method to make the evaluation and ignore the alternative methods. Maybe the results are subjective. We could consider the other alternative methods and do some comparison and then choose an optimal method to do the relative research in the future. Besides, there are incomplete problems in the summary of the demand types; we need to improve in the follow-up studies.

\section{Data Availability}

The data used to support the findings of this study are included within the article.

\section{Conflicts of Interest}

The authors declare that there are no conflicts of interest regarding the publication of this manuscript.

\section{Acknowledgments}

This research work was supported by the Program for the Philosophy and Social Sciences Research of Higher Learning Institutions of Shanxi (nos. 2017326 and 2016241) and the Shanxi Scholarship Council of China (no. 2017-102).

\section{References}

[1] H. W. Bullamore, "Three types of poverty in metropolitan Indianapolis," Geographical Review, vol. 64, no. 4, pp. 536$556,1974$.

[2] T. Reardon and S. A. Vosti, "Links between rural poverty and the environment in developing countries: asset categories and investment poverty," World Development, vol. 23, no. 9, pp. 1495-1506, 1995.

[3] S. Li and J. Knight, "Three poverties in urban China," Economic Research Journal, vol. 10, pp. 47-58, 2002. 
[4] K. Lin and X. G. Fan, "Poverty and anti-poverty-a study on the changes of poverty types and anti-poverty policies in China," Social Science Front, vol. 29, no. 1, pp. 187-194, 2006.

[5] X. Luo, "A summary of studies on China's poverty since the mid-1980s,” Academics, vol. 22, no. 6, pp. 247-257, 2007.

[6] G. J. Chen, "An analysis of the attitude, characteristics of rural poverty in China and the determinants," Chinese Rural Economy, vol. 24, no. 9, pp. 13-25, 2008.

[7] J. H. Zhu and D. F. Cui, "Study on poverty types and countermeasures of state poverty countries in Xinjiang under new situation," Research of Agricultural Modernization, vol. 32, no. 3, pp. 276-280, 2011.

[8] H. Liu, "A new analysis of China's rural poverty alleviation from absolute to relative shift-an analysis based on precise poverty alleviation background," Soft Science, vol. 21, 31, no. 5, pp. 11-15, 2017.

[9] B. Belhadj and M. Limam, "Unidimensional and multidimensional fuzzy poverty measures: new approach," Economic Modelling, vol. 29, no. 4, pp. 995-1002, 2012.

[10] S. G. Wang and Z. H. Guo, "Precise poverty alleviation in China," Guizhou Social Sciences, vol. 36, no. 5, pp. 147-150, 2015.

[11] M. Y. Yi, "Xi Jinping's thought on taking targeted measures in poverty alleviation," Guizhou Social Sciences, vol. 37, no. 5, pp. 139-144, 2016.

[12] W. J. Li, C. M. Shuai, J. Shuai, X. Cheng, L. P. Ding, and M. M. Li, "Evaluation on precision poverty eradication effects of IFAD projects in rural China based on household asset index," China Soft Science, vol. 31, no. 7, pp. 66-77, 2016.

[13] C. M. Shuai, W. J. Li, X. Cheng, J. Shuai, L. P. Ding, and $\mathrm{X}$. Tao, "Estimation on poverty reduction efficiency of IFADsupported projects in rural China: based on panel date of 1356 farmer households in seven provinces," Management World, vol. 32, no. 3, pp. 73-86, 2016.

[14] S. G. Wang, A. Park, S. Chaudhuri, and G. Datt, "China’s rural poverty alleviation in the new period and the village poverty targeting," Management World, vol. 32, no. 3, pp. 73-86, 2016.

[15] A. Park, S. Wang, and G. Wu, "Regional poverty targeting in China," Journal of Public Economics, vol. 86, no. 1, pp. 123153, 2002.

[16] A. Hagenaars, "A class of poverty indices," International Economic Review, vol. 28, no. 3, pp. 583-607, 1987.

[17] X. L. Wang and S. Alkire, "Multidimensional poverty in China: estimation and policy implications," Chinese Rural Economy, vol. 25, no. 12, pp. 4-10, 2009.

[18] C. Z. Lu, "Who is poor in China? A comparison of alternative approaches to poverty assessment in rural Yunnan," Journal of Peasant Studies, vol. 37, no. 2, pp. 407-428, 2010.

[19] J. L. Li, "Measurement of multidimensional poverty of rural household-case studies based on 30 selected counties with severe poverty in S province," Finance \& Trade Economics, vol. 31, no. 10, pp. 63-68, 2010.

[20] S. Alkire and J. Foster, "Counting and multidimensional poverty measurement," Journal of Public Economics, vol. 95, no. 7-8, pp. 476-487, 2011.

[21] W. Zou and Y. F. Fang, "A study on the dynamic multidimensional measurement of China's poverty," Chinese Journal of Population Science, vol. 25, no. 6, pp. 49-59, 2011.

[22] C. X. Jiang, Q. F. Xu, and Y. Q. Li, “A statistical measurement of multidimensional poverty in China," Statistics \& Decision, vol. 27, no. 22, pp. 92-95, 2011.

[23] J. Y. Guo, "Analysis on the degree and characteristics of farmers' multidimensional poverty-based on Shanxi rural poverty monitoring data," Rural Economy, vol. 30, no. 3, pp. 19-22, 2012.

[24] X. L. Sun, G. Y. Tian, Y. Pan, Z. Zhang, and W. L. Zhang, "Research on rural poverty measurement in China-based the data of Shanxi province," On Economic Problems, vol. 34, no. 4, pp. 79-84, 2012.

[25] Q. Chen, "The multidimensional measurement and the policy implication of the rural poverty in the poverty-stricken covered areas," Journal of Sichuan Normal University (Social Sciences Edition), vol. 39, no. 3, pp. 58-63, 2012.

[26] Y. Y. Gao and Y. Ma, "The dynamic research on the poverty for Chinese household based on the multidimensional framework," Statistical Research, vol. 30, no. 12, pp. 89-94, 2013.

[27] Y. H. Wang, L. Y. Qian, F. Z. Duan, and W. J. Zhao, "An analysis on multidimensional poverty measurement and research on its spatial distribution pattern: a case study from Neixiang County," Population \& Economics, vol. 35, no. 5, pp. 114-120, 2014.

[28] L. Yang and S. G. Wang, "Multidimensional poverty measurement and decomposition of households in poor area$\mathrm{s}$-based on the China rural poverty monitoring household survey in 2010," Population Journal, vol. 37, no. 2, pp. 15-25, 2015.

[29] L. L. He, Z. Zuo, and Y. P. Luo, "Implementation of precision poverty reduction recognition by multi dimension poverty measure-investigation of 50 poverty-stricken counties in Guizhou province," Economic Review, vol. 37, no. 7, pp. 4752, 2016.

[30] L. Wang and G. Y. Wu, "A study on the recognition mechanism of the poverty population in China's rural areas from the perspective of precise poverty alleviation," Rural Economy, vol. 34, no. 7, pp. 112-117, 2016.

[31] G. Betti, R. Soldi, and I. Talev, "Fuzzy multidimensional indicators of quality of life: the empirical case of Macedonia," Social Indicators Research, vol. 127, no. 1, pp. 39-53, 2016.

[32] B. Belhadj, "New weighting scheme for the dimensions in multidimensional poverty indices," Economics Letters, vol. 116, no. 3, pp. 304-307, 2012.

[33] G. Betti, B. Cheli, A. Lemmi, and V. Verma, "The fuzzy approach to multidimensional poverty: the case of Italy in the 1990s," in Quantitative Approaches to Multidimensional Poverty Measurement, N. Kakwani and J. Silber, Eds., Palgrave Macmillan, London, UK, pp. 30-48, 2008.

[34] L. A. Zadeh, "Fuzzy sets," Information and Control, vol. 8, no. 3, pp. 338-353, 1965.

[35] B. Belhadj, "A new fuzzy unidimensional poverty index from an information theory perspective," Empirical Economics, vol. 40, no. 3, pp. 687-704, 2011.

[36] G. Betti and V. Verma, "Fuzzy measures of the incidence of relative poverty and deprivation: a multi-dimensional perspective," Statistical Methods and Applications, vol. 17, no. 2, pp. 225-250, 2008.

[37] B. Cheli, "Totally fuzzy and relative measures in dynamics context," Metron, vol. 53, pp. 83-205, 1995.

[38] B. Cheli and A. Lemmi, "A totally fuzzy and relative approach to the multidimensional analysis of poverty," Economic Notes, vol. 24, pp. 115-134, 1995.

[39] A. Cerioli and S. Zani, "A fuzzy approach to the measurement of poverty," in Income and Wealth Distribution, Inequality and Poverty, C. Dagum and M. Zenga, Eds., pp. 272-284, Springer-Verlag, Berlin, Germany, 1990.

[40] T. Besley and R. Kanbur, "Food subsidies and poverty alleviation," The Economic Journal, vol. 98, no. 392, pp. 701-719, 1988. 
[41] F. Ellis and H. A. Freeman, "Rural livelihoods and poverty reduction strategies in four african countries," Journal of Development Studies, vol. 40, no. 4, pp. 1-30, 2004.

[42] M. Mendola, "Agricultural technology adoption and poverty reduction: a propensity-score matching analysis for rural Bangladesh," Food Policy, vol. 32, no. 3, pp. 372-393, 2007.

[43] D. Harrison, S. Schipani, and C. M. Hall, "Lao tourism and poverty alleviation: community-based tourism and the private sector," Current Issues in Tourism, vol. 10, no. 2-3, pp. 194-230, 2007.

[44] H. Goodwin, "Tourism and poverty reduction," Annals of Tourism Research, vol. 38, no. 1, pp. 339-340, 2011.

[45] A. Yadoo and H. Cruickshank, "The role for low carbon electrification technologies in poverty reduction and climate change strategies: a focus on renewable energy mini-grids with case studies in Nepal, Peru and Kenya," Energy Policy, vol. 42, no. 1, pp. 591-602, 2012.

[46] W. J. Deng, "The difficulties, countermeasures and paths of precise poverty alleviation," Rural Economy, vol. 32, no. 6, pp. 78-81, 2014.

[47] H. Manwa and F. Manwa, "Poverty alleviation through propoor tourism: the role of Botswana forest reserves," Sustainability, vol. 6, no. 9, pp. 5697-5713, 2014.

[48] Y. Y. Yang, Y. S. Liu, and Z. W. Zhang, "Study on policy innovation and suggestions of targeted poverty alleviation based on typical investigation," Bulletin of Chinese Academy of Sciences, vol. 31, no. 3, pp. 337-345, 2016.

[49] C. W. Chen and C. G. Li, "On the integrating degree of policy of targeted poverty alleviation to the demand of rural poor population," Shandong Social Sciences, vol. 31, no. 3, pp. 42-48, 2017.

[50] S. Jing, Y. Yang, Z.-P. Ho, J. Yan, and H.-T. Huang, "The development of a frame model for management strategies selection using fuzzy proximity," Cluster Computing, vol. 20, no. 1, pp. 141-153, 2017.

[51] F. Gao, S. Jiang, and Y. N. Li, "Judgment method of industrial cluster's life cycle based on fuzzy proximity," Computer Integrated Manufacturing Systems, vol. 20, no. 12, pp. 30973103, 2014.

[52] F. D. Yang, Z. W. Niu, and S. W. Jing, "Judgement method of advancing stage to propel enterprise lean management based on fuzzy nearness," Journal of Tianjin University (Social Sciences), vol. 18, no. 3, pp. 200-205, 2016.

[53] Z. S. Hua and L. Liang, "Multi-subjective classification algorithm based on fuzzy proximity," Operations Research and Management Science, vol. 33, no. 3, pp. 19-24, 1994.

[54] K. Jia and J. Sun, "PPP management mode should be introduced in new rural construction," Scientific Decision Making, vol. 13, no. 7, pp. 16-17, 2006.

[55] E. C. Hui, "Rural infrastructure construction financing in China," Issues in Agricultural Economy, vol. 33, no. 7, pp. 63-69, 2012.

[56] A. Sen, "Capability and well-being in Nussbaum," The Quality of Life, Clarendon Press, Oxford, UK, pp. 30-53, 1993.

[57] L. M. Fang and X. L. Zhang, "The analysis on the poverty alleviation policy in rural China: based on capability poverty theory," Journal of Finance and Economics, vol. 52, no. 12, pp. 47-57, 2007.

[58] X. L. Zhang, Y. B. Xu, and L. M. Fang, "Thirty years of reforms and opening-up: China's social security system in rapid social changes," Journal of Beijing Normal University (Social Sciences), vol. 54, no. 2, pp. 120-128, 2009. 


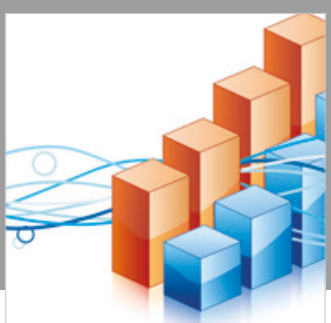

Advances in

Operations Research

\section{-n-m}
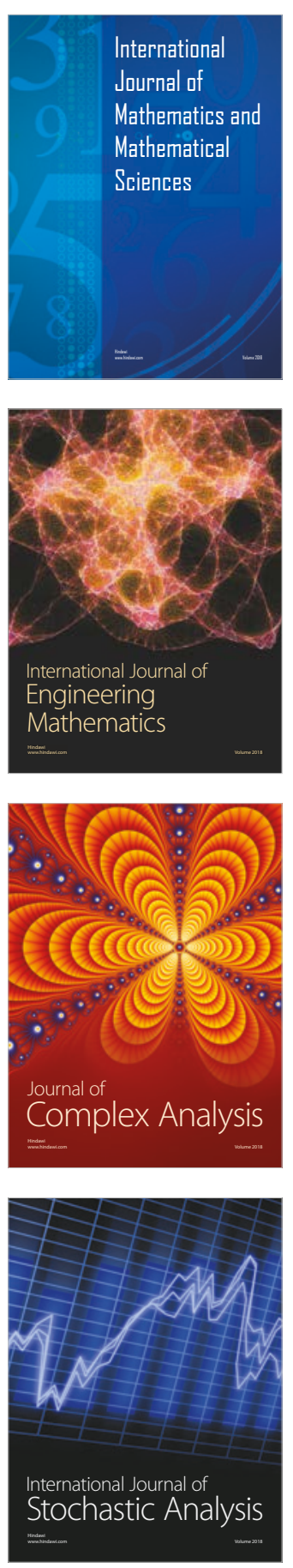
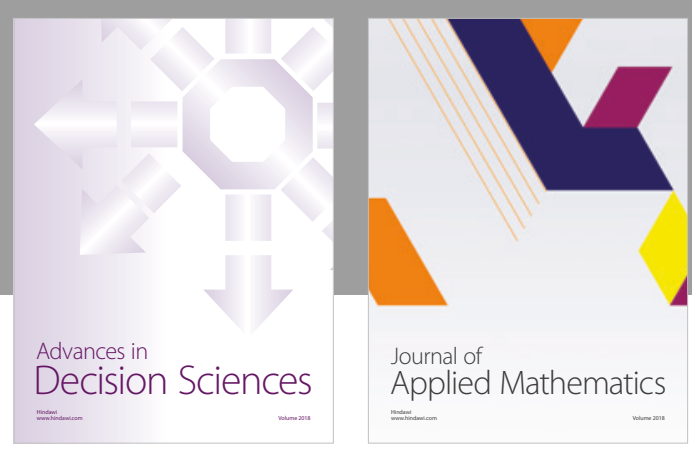

Journal of

Applied Mathematics
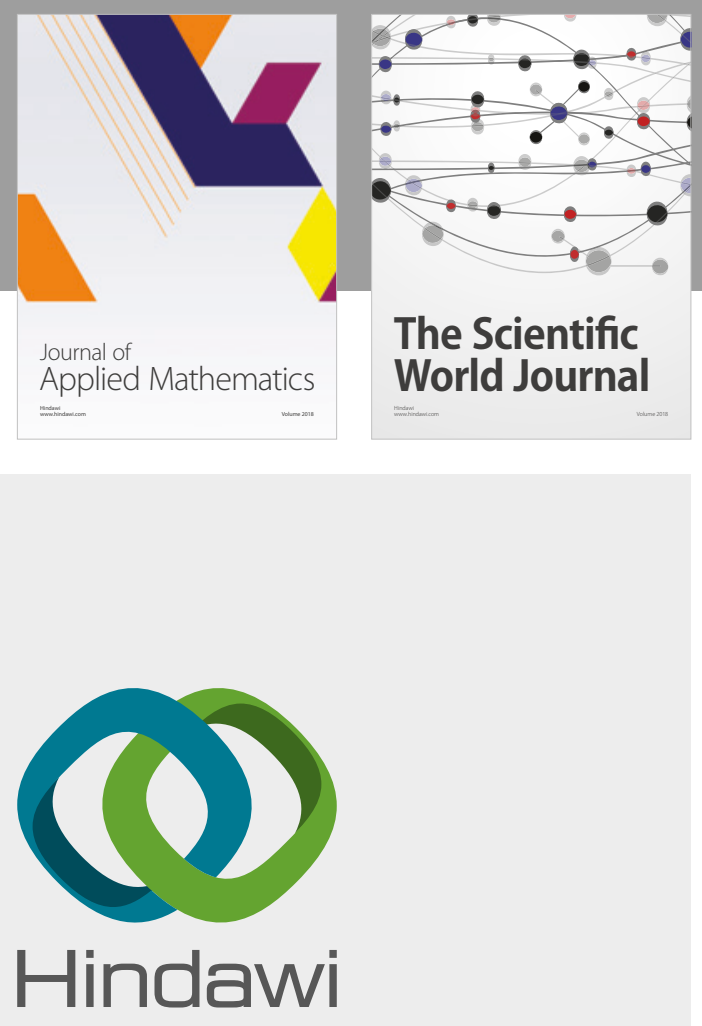

Submit your manuscripts at

www.hindawi.com

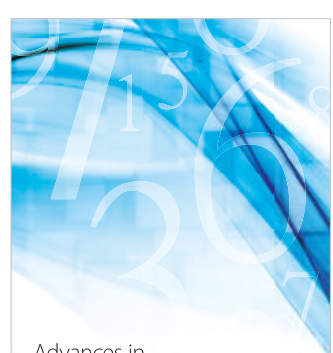

Advances in
Numerical Analysis
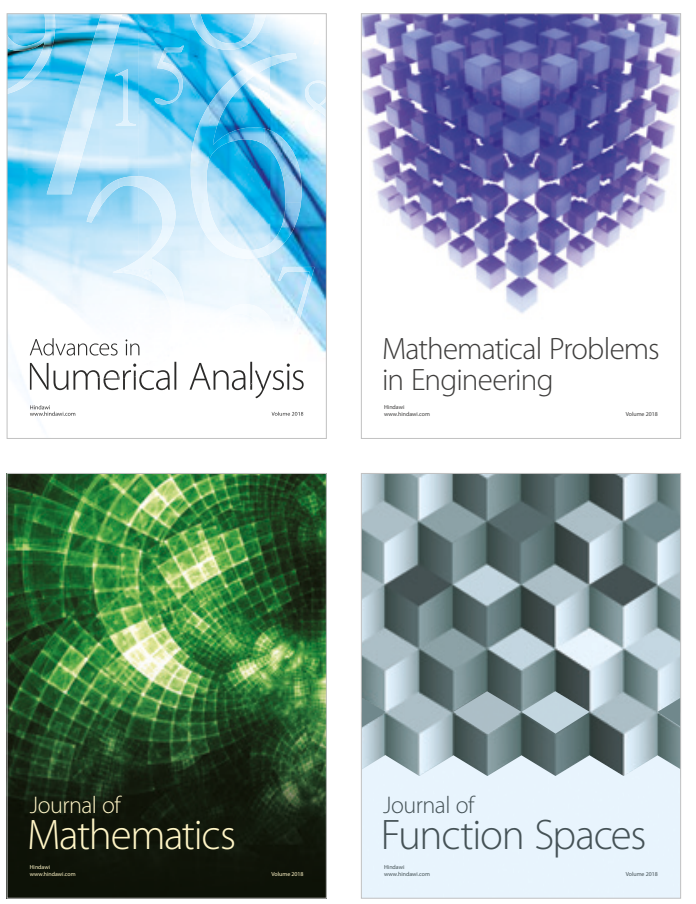

Mathematical Problems in Engineering

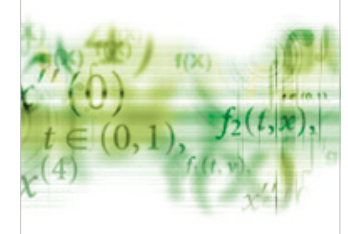

International Journal of

Differential Equations

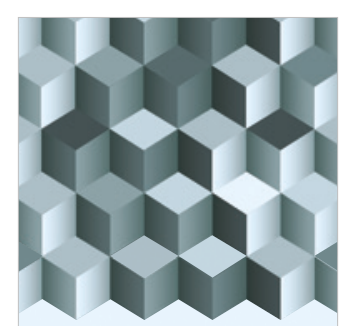

Journal of

Function Spaces
The Scientific

World Journal

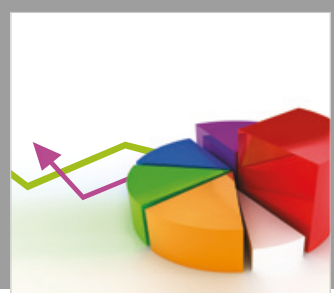

Journal of

Probability and Statistics
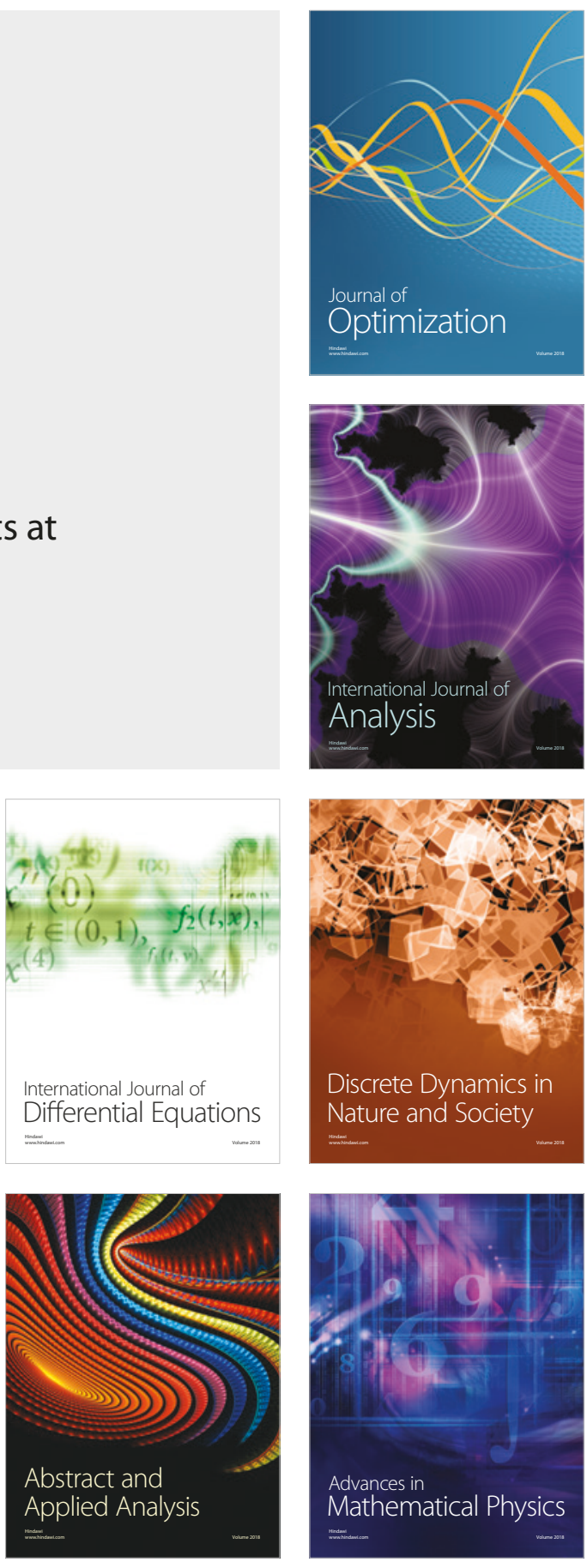